\title{
Is a High Level of Cholesterol or Vitamin D Deficiency a Risk Factor for Dental Implants or Bone Grafting Failure?
}

\author{
Hassan H Koshak* \\ Periodontist and Implantologist, Saudi Arabia
}

Submission: September 14, 2017; Published: September 21, 2017

*Corresponding author: Hassan H Koshak, Head of the Dental Department and Dental Educator at Comprehensive Specialized Polyclinic, Ministry of Interior Security Forces Medical Services, Jeddah, Kingdom of Saudi Arabia, P.O. Box 108999, Jeddah 21352, KSA, Tel: +966 (0) 555507035 ; Email: Koshak.hh@gmail.com

\section{Introduction}

The search for a biological anomaly labeled as a risk factor before dental implants is limited to disease states such as diabetes, periodontitis and smoking. However, it seems in recent years cholesterol and vitamin $\mathrm{D}$ levels should be more systematically investigated [1]. There is also clearly a close relationship between cholesterol, and vitamin D. It is interesting to note that cholesterol and vitamin D have the same precursor, namely, 7- Dehydrocholesterol [2]. There is good cholesterol (high-density lipoprotein [HDL]) and bad cholesterol (lowdensity lipoprotein [LDL]) [3]. Vitamin D is one of the most important vitamins related to bone growth hormones. In addition, vitamin $\mathrm{D}$ also plays a role in reducing the effects of inflammation and helps improve the body's natural immune reactions [4].

\section{Cholesterol and Bone Metabolism}

A. What is the role of LDL?: According to Luegmayr et al, 2004 elevated levels of cholesterol may lead to an imbalance in the bone-remodeling process, a reduction of bone mass by increasing the activity, and a differentiation of osteoclasts [5]. Krieger 1998 [6] demonstrated an increase in the number of osteoclasts, the inhibition of osteoblastic activity, and a decreased bone remodeling in hyperlipidemic rats. An increase of circulating levels of oxidized LDL induces alveolar bone loss and is associated with the severity of the local inflammatory response to bacteria as well as the susceptibility to periodontal disease in diabetic patients [7].

The bone releases enzymes that are involved in the oxidation of LDL. It is possible that the oxidized LDL accumulated in the bone could induce subsequent deleterious cellular effects on bone density [8]. Hyperlipidemia causes a reduction of bone density in vivo due to the inhibition of osteoblast differentiation by bioactive lipids [9]. Oxidized LDL caused an inhibition of the alkaline phosphatase activity and also mineralization, which are markers of osteoblast differentiation. In addition, it has recently been shown that oxidized LDL also induces cell death by apoptosis of osteoblastic cells [10]. Hirasawa et al. [11] 2007 confirmed that atherogenic conditions (high LDL levels) caused the death of osteoblasts. Oxidized low-density lipoprotein particles have been shown both to stimulate the proliferation and promote apoptosis of bone-forming osteoblasts [12].

Oxidized low density lipoproteins (OxLDL) are known to promote atherosclerosis, but it is only recently that OxLDL have been associated with alterations of the functions of bone-forming osteoblasts and osteoporosis. HDL3 prevent the cell death induced by OxLDL in human osteoblastic cells. Simultaneous exposure of the cells to HDL3 and OxLDL abolished the reduction of cell viability monitored by MTT activity measurement and the induction of apoptosis determined by annexin V staining indicating that HDL3 prevent the apoptosis of osteoblasts induced by OxLDL. This protection correlated with the displacement by HDL3 of OxLDL association to osteoblasts, signifying that OxLDL binding and/or internalization are/is necessary for their cytotoxic effects [13].

B. What is the role of HDL?: Various antioxidants carried by HDL may interrupt the cascade of events leading to the oxidation of LDL [14]. Another important property of HDL is its ability to inhibit cell death induced by oxidized LDL In particular, it has been reported that HDL inhibits the apoptosis of monocytic cells by inducing cholesterol efflux and thus preventing the accumulation of cholesterol caused by the presence of oxidized LDL. HDL should be considered as a bone cell protector [15]. Brodeur et al. 2008 found that osteoblastic cells to HDL3 prior to incubation with OxLDL reduced cell death and preserved the lysosomal integrity. 
This protection was correlated with an increase of a modification of OxLDL metabolism with less global uptake of OxLDL and greater selective uptake of cholesterol from OxLDL. These results strongly suggest that, as for atherosclerosis, HDL may exert beneficial actions on bone metabolism [13]. Osteoclasts depend on lipoproteins to modulate cellular cholesterol levels and this controls osteoclasts formation and survival. Removal of cholesterol in osteoclasts via high-density lipoprotein or cyclodextrin treatment dose-dependently induced apoptosis, with actin disruption, nuclear condensation and activation. Consistent with these findings, cholesterol delivery via lowdensity lipoprotein (LDL) significantly increased osteoclasts viability. When cholesterol was chemically delivered during differentiation with hyperlipidemia being associated with disease of the vascular system and bone, these findings provide novel insights into the selective lipoprotein and cholesterol dependency of the bone-resorbing cell [16].

Table 1: Serum level values.

\begin{tabular}{|lc|}
\hline \multicolumn{2}{|c|}{ Lipoprotein values } \\
\hline Cholesterol total & $<2 \mathrm{~g} / \mathrm{L}$ \\
\hline Triglycérides & $<2 \mathrm{~g} / \mathrm{L}$ \\
\hline LDL cholesterol & Men $<1.6 \mathrm{~g} / \mathrm{L} \mathrm{Wamen}<1.5 \mathrm{~g} / \mathrm{L}$ \\
\hline HDL cholesterol & $>0.35 \mathrm{~g} / \mathrm{L}$ \\
\hline
\end{tabular}

C. What is the Serum level of lipoprotein?: Serum level values are shown in Table 1. The result of high LDL is a reduction of bone metabolism, inhibition of phosphatase alkaline, and an increase of the fat part in the bone. The result is a lower osseointegration and slower bone growth [1]. Branemark said in 1985, during an international meeting, «When I see a yellow bone, I cancel the transplant!» At that time, it was only a clinical observation [1]. We now understand why. We have been focused on the high cholesterol risk in bone grafts for more than 10 years, and now we can explain why we had more failures in these cases [1].

A retrospective cohort study done by Federico et al. 2016 was conducted on 268 sequential patients scheduled for implant and bone augmentation surgery, patients were divided into two groups: Total serum cholesterol (TC) TC $<200 \mathrm{mg} / \mathrm{dl}$ and TC $>$ $200 \mathrm{mg} / \mathrm{dl}$. A 6-month post-loading follow-up was scheduled both for implants and grafts. The effect of cholesterol on early implant and grafting failure was investigated according to a logistic regression model. The Results was two hundred and twenty-seven patients fulfilled inclusion criteria; 139 had hypercholesterolemia. The 6-month post-loading overall implant failure rate was $6.25 \%$ at patient level (2.00\% at implant level).

Partial or total graft infection rate was $10.2 \%$. High TC increased by 7.48 times the odds of the grafting failure $(\mathrm{P}=$ 0.047; 95\% CI: -0.94 to 59.23), whilst it did not modify the odds of implant failure ( $\mathrm{P}=0.749$; $95 \% \mathrm{CI}: 0.28$ to 2.49 ). Federico conclusion was high total serum cholesterol levels tend to increase graft failure rates whilst it did not influence implant failures [17]. Kırzıoglu et al. [18] 2016 didexperimentalstudy on rats were randomized into the four groups:1-group C (standard diet/periodontally healthy); 2-group Hc(high-cholesterol diet); 3-group HcP (high-cholesterol diet/periodontitis); and 4-group $\mathrm{P}$ (standard diet/periodontitis).

All rats were fed for 8 weeks. At 6 weeks, experimental periodontitis was induced. At the end of week 8 , the rats were sacrificed. Histomorphometric and histopathologic analyses were performed. The result was significant in the HcP group a high-cholesterol diet, with or with- out periodontitis. Kırzıoglu concludedcholesterol-enriched diet could lead to an increase in periodontal inflammation and alveolar bone loss [18].

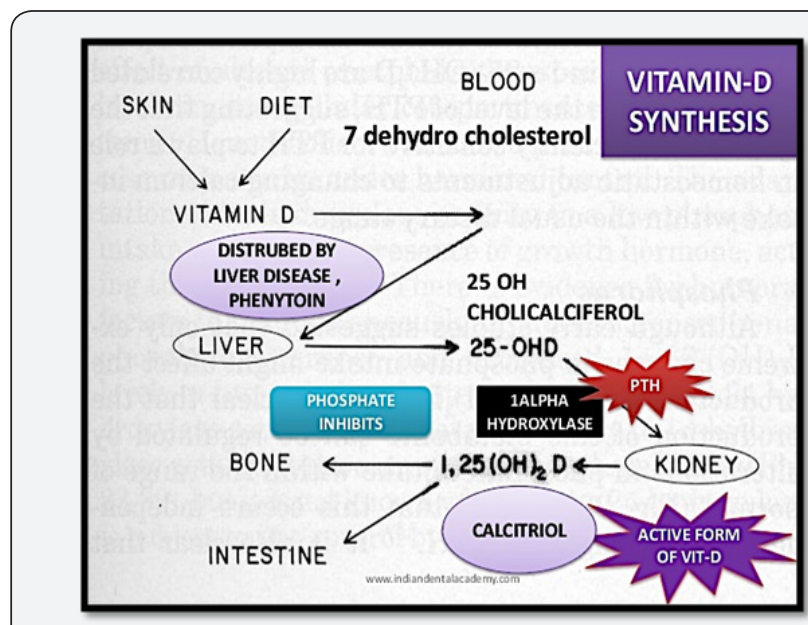

Figure 1: Vitamin D Synthesis.

D. Low vitamin D incidence on osseointegration and bone grafts: The most important related compound of vitamin D is vitamin D3 (cholecalciferol) (25-hydroxyvitamin, 250HD3). Vitamin D is a steroid hormone that is acquired via diet or synthesized in the skin from cholesterol when sun (ultraviolet light) exposure is adequate (Figure 1) [19]. Cholesterol is converted to pre-vitamin D3 and then isomerized to vitamin D3. After binding to vitamin D-binding carrier protein, vitamin D3 is transported to the liver, where it is enzymatically hydroxylated by CYP27A1, generating 25-hydroxyvitamin D3 (calcidiol, or 250HD3) [19].

In the bone, vitamin D stimulates the activity of osteoclasts and increases the production of extracellular matrix proteins by osteoblasts. Vitamin D also stimulates intestinal calcium absorption and inhibits the synthesis and secretion of parathyroid hormone [20]. Vitamin D deficiency can result from inadequate dietary intake together with the insufficient exposure to sunlight. Vitamin D deficiency in these patients is associated with a catabolic bone turnover and its main consequence, the occurrence of osteoporotic fractures [21]. Vitamin D deficiency has also been linked to impaired fracture healing in clinical practice and in patients suffering a fracture [22]. These results support the role of the steroid hormone in controlling bone regeneration. 
As osseointegration of dental implants also depends on bone regeneration, periimplant bone formation was shown to be reduced in vitamin D deficient rats [23]. Dvorak et al. [24] 2012 indicated that vitamin D deficiency has a negative impact on cortical peri-implant bone formation in ovariectomized rats, which can be compensated by a vitamin D-rich diet. Vitamin D has also been implicated in several allergic disorders and immune system dysregulation. It has extensive immunomodulatory effects. It is now known that cells from the immune system contain all the characteristics needed to convert 25-hydroxy vitamin $\mathrm{D}$ to active 1,25-dihydroxyvitamin $\mathrm{D}$ during a bacterial infection [4].

These peptides have a broad range of actions against microorganisms, including bacteria, fungi, and viruses [25]. Frieri and Valluri, 2011 showed that there was also a positive correlation with allergy subtypes and sinus infections with low vitamin D [26]. Flynn et al. [25] 2012 showed that vitamin D levels $<20 \mathrm{ng} / \mathrm{mL}$ have a significant impact on length of stay, organ dysfunction, and infection rates. Vitamin D has since been studied in several clinical trials to characterize its role in respiratory infections [27]. Vitamin D also plays a predominant role in allergy. Numerous data are published on the relationship between vitamin $\mathrm{D}$ and asthma and allergic patients are often deficient in vitamin D [28,29].

Table 2: Serum level values.

\begin{tabular}{|lr|}
\hline \multicolumn{2}{|c|}{ Vitamin D levels } \\
\hline \multicolumn{2}{|c|}{ Deficiency $<10 \mathrm{ng} / \mathrm{mL}$} \\
\hline Insufficiency & $10-30 \mathrm{ng} / \mathrm{mL}$ \\
\hline Optimal & $>30 \mathrm{ng} / \mathrm{mL}$ \\
\hline
\end{tabular}

E. What is the Serum level of vitamin D?: Serum level values are shown in Table 2. Daily needs of vitamin D are $4000 \mathrm{IU}$, and the lack of sufficient vitamin D in one's diet is very common: An estimated 1 billion people worldwide are vitamin D deficient [21]. Maier et al. [30] 2013 asked: Is there an epidemic vitamin D deficiency in German orthopedic patients? Among preoperative orthopedic patients, he found that $85 \%$ were insufficient and $60 \%$ were deficient. Sabetta et al. [31] 2010 conducted a prospective cohort study showing that serum 25(OH)D concentrations of $38 \mathrm{ng} / \mathrm{mL}$ or greater were associated with a 2 -fold decrease in the number of upper respiratory infections. Vitamin D deficiency has been also implicated in various diseases such as diabetes, high blood pressure, cardiovascular diseases, and many cancers [20]. Vitamin D serum level plays a predominant role in bone metabolism, sensibility to infections, and many allergy symptoms [29]. Vitamin D may also affect the body's susceptibility and response to infectious organisms, a major trigger of wheezing at a young age [28].

F. The supplementation of vitamin $D$ in a daily diet also decreases the LDL cholesterol: The link between osteoporosis and the metabolic syndrome could influence the therapeutic approach in both disorders and vitamin D.
Supplementation may play an important role in prevention of these severe conditions [32]. Dvorak et al. [33] 2012 did a study on ovariectomized rats and he found in his results vitamin D deficiency has a negative impact on cortical peri-implant bone formation in ovariectomized rats, which can be compensated by vitamin D supplementation. We suggest exploring vitamin D serum level and LDL Cholesterol systematically in patients who are diabetic, allergic, with hypertension, and previously in a difficult case of implants and/or bone grafting. This exploration is largely indicated in the cases of a failure of bone graft or implant placement [1].

\section{Conclusion}

The assessment of the total serum cholesterol levels and vitamin D status, it is indicated and necessary for dental implants or bone grafts patient.

\section{References}

1. Choukroun Joseph, Fouad Khoury, Philippe Russe, Tiziano Testori, Yátaro Komiyama, et al. (2014) Two Neglected Biologic Risk Factors in Bone Grafting and Implantology. Journal of Oral Implantology 40(1): 110-114.

2. Grimnes G, Jorde R, Simonsen GS, Furberg AS (2012) Staphylococcus aureus nasal carriage is associated with serum 25- hydroxyvitamin D levels, gender and smoking status. The Tromsø Staph and Skin Study. Eur J Gin Microbiol Infect Dis 31: 465- 473.

3. Krieger Monty (1998) The "best" of cholesterols, the "worst" of cholesterols: A tale of two receptors. Proc Natl Acad Sci USA 95: 40774080.

4. Hewison M (2012) Vitamin D and immune function: autocrine, paracrine or endocrine? Scand J Gin Lab Invest Suppl 243:92- 102.

5. Luegmayr E, Glantschnig H, Wesolowski GA, Gentile MA, Fisher JE, et al. (2004) Osteoclast formation, survival and morphology are highly dependent on exogenous cholesterol/lipoproteins. Cell Death Differ 11(1): S108-S118.

6. Krieger Nace, Zhenqiang Yao, Kelly Kyker-Snowman, Min Ho Kim, Brendan F Boyce, et al. (2016) Increased bone density in mice lacking the proton receptor, OGR1. Kidney Int 89(3): 565-573.

7. Tomofuji Takaaki, Daisuke Ekuni, Tetsuji Azuma, KoichiroIrie, Yasumasa Endo, et al. (2013) Involvement of toll-like receptor 2 and 4 in association between dyslipidemia and osteoclast differentiation in apolipoprotein E deficient rat periodontium. Lipids in Health and Disease 12: 1-6.

8. Hansdottir S, Monick MM (2011) Vitamin D effects on lung immunity and respiratory diseases. Vitam Horm 86: 217-237.

9. Brodeur MR (2009) Implication des Lipoprotéinesdans le métabolisme normal etpathologique du tissuosseux [PhD thesis]. Montreal, Canada: University Montreal Canada.

10. Klein BY, Rojansky N, Ben-Yehuda A, Abou-Atta I, Abedat S, et al. (2003) Cell death in cultured human Saos2 osteoblasts exposed to low-density lipoprotein. Cell Biochem 90: 42-58.

11. Hirasawa H, Tanaka S, Sakai A (2007) ApoE gene deficiency enhances the reduction of bone formation induced by a high-fat diet through the stimulation of p53-mediated apoptosis in osteoblastic cells. Bone Miner Res 22: 1020-1030.

12. Hamel P, E Abed, L Brissette, R Moreau (2008) Characterization of oxidized low-density lipoprotein-induced hormesis-like effects in osteoblastic cells. American Journal of Physiology - Cell Physiology 294(4): C1021-C1033. 
13. Brodeur MR, Brissette L, Falstrault L, Luangrath V, Moreau R (2008) Scavenger receptor of class B expressed by osteoblastic cells are implicated in the uptake of cholesteryl ester and estradiol from LDL and HDL3. J Bone Miner Res 23: 326-337.

14. Navab M, Ananthramaiah GM, Reddy ST (2004) The oxidation hypothesis of atherogenesis: the role of oxidized phospholipids and HDL. Lipid Res 45: 993-1007.

15. Jiang P, Yan PK, Chen JX (2006) High density lipoprotein 3 inhibits oxidized low density lipoprotein-induced apoptosis via promoting cholesterol effiux in RAW264.7 cells. Acta Pharmacol Sin 27: 151-157.

16. Luegmayr E, H Glantschnig, GA Wesolowski, MA Gentile, JE Fisher, et al. (2004) Osteoclast formation, survival and morphology are highly dependent on exogenous cholesterol/ lipoproteins. Cell Death and Differentiation 11: S108-S118.

17. Federico Tirone, Stefano Salzano, Lodovico D’orsi, Panuello Paola, Donata Rodi (2016) Is a high level of total cholesterol a risk factor for dental implants or bone grafting failure?

18. Kırzıoğlu FY, Fentoğlu Ö, Bulut MT, Doğan B, Özdem M, et al. (2016) Is a Cholestrol-Enriched Diet a Risk Factor for Alveolar Bone Loss? J Periodontol 87(50): 529-538.

19. Lehmann B (2005) The vitamin D3 pathway in human skin and its role for regulation of biological processes. Photochem Photobiol 81: 1 2461251.

20. Dusso AS, Brown AJ, Slatopolsky E (2005) Vitamin D. Am J Physiol Renal Physiol 289: F8-F2.

21. Holick M (2007) Vitamin D deficiency. N EngI J Med 357: 266-281.

22. Brinker MR, O’Connor DP, Monia YT, Earthman TP (2007) Metabolic and endocrine abnormalities in patients with nonunions. J Orthop Trauma 21: 557-570.

23. Kelly J, Lin A, Wang CJ, Park S, Nishimura I (2009) Vitamin D and bone physiology: demonstration of vitamin D deficiency in an implant osseointegration rat model. J Prosthodont 8: 473-478.
24. Dvorak G, Fügl A, Watzek G, Tangi S, Pokorny P, et al. (2012) Impact of dietary vitamin $\mathrm{D}$ on osseointegration in the ovariecto- mized rat. Gin Oral Implants Res 23: 1308-1313.

25. Flynn L, Zimmerman LH, McNorton K (2012) Effects of vitamin D deficiency in critically ill surgical patients. Am J Surg 203: 379-382.

26. Frieri M, Valluri A (2011) Vitamin D deficiency as a risk factor for allergic disorders and immune mechanisms. Allergy Asthma Proc 32: 438-444.

27. Youssef DA, Miller CW, El-Abbassi AM (2011) Antimicrobial implications of vitamin D. Dermatoendocrinol 3: 220-229.

28. Reinholz M, Ruzicka T, Schauber J (2012) Vitamin D and its role in allergic disease. Gin Exp Allergy 42: 817-826.

29. Bozzetto S, Carraro S, Giordano G, Boner A, Baraldi E (2012) Asthma, allergy and respiratory infections: the vitamin D hypothesis. Allergy 67: 10-17.

30. Maier GS, Jakobs P, Roth KE, Kurth AA, Maus U (2013) Is there an epidemic vitamin D deficiency in German orthopaedic patients? Gin OrthopRelat Res 471: 3029-3035.

31. Sabetta JR, De Petrillo P, Cipriani RJ, Smardin J, Burns LA, et al. (2010) Serum 25-hydroxyvitamin D and the incidence of acute viral respiratory tract infections in healthy adults. PLoS One 5: el 1088.

32. Major GC, Alarie F, Doré J, Phouttama S, Tremblay A (2007) Supplementation with calcium -(-vitamin D enhances the beneficial effect of weight loss on plasma lipid and lipoprotein concentrations. Am J Gin Nutr 85: 54-59.

33. Dvorak Gabriella, AL expander Fugi, GerogWatzek, Stefan Tangl, Petra Pokorny, et al. (2012) Impact of dietary vitamin D on osseointegration in the ovariectomized rat. Clinical Oral Implants Research 23: 13081313.

Your next submission with Juniper Publishers
will reach you the below assets
- Quality Editorial service
- Swift Peer Review
- Reprints availability
- E-prints Service
- Manuscript Podcast for convenient understanding
- Global attainment for your research
- Manuscript accessibility in different formats
( Pdf, E-pub, Full Text, Audio)
- Unceasing customer service
Track the below URL for one-step submission
https://juniperpublishers.com/online-submission.php

